\title{
Agregados plaquetários e a sua utilização na odontologia
}

\author{
Platelet aggregation and its use \\ in odontology
}

\section{Laize Emanuelle da Silva Alves ${ }^{1}$ Mônica Dourado Silva Barbosa ${ }^{2}$ (1)}

\author{
1Autora para correspondência. Escola Bahiana de Medicina e Saúde Pública (Salvador). Bahia, Brasil. lai-emanuelle@hotmail.com
} ${ }^{2}$ Escola Bahiana de Medicina e Saúde Pública (Salvador). Bahia, Brasil. monicadourado@bahiana.edu.br

\begin{abstract}
RESUMO | O reparo tecidual consiste na propriedade do organismo em curar uma ferida recuperando a continuidade do tecido afetado. A fibrina apresenta um importante papel no processo de regeneração tecidual, sendo definida como uma proteína fibrosa que atua no processo de coagulação sanguínea, promovendo agregação plaquetária durante a homeostasia. Visando uma melhoria no processo de regeneração tecidual, alguns agregados plaquetários estão sendo utilizados na odontologia, sendo eles Plasma Rico em Plaquetas (PRP) e Fibrina Rica em Plaquetas (PRF). O objetivo deste trabalho é, através de uma revisão de literatura discutida, analisar as propriedades dos agregados plaquetários, em especial da PRF e a sua utilização na odontologia. A primeira geração de agregados plaquetários autólogos foi denominado de Plasma Rico em Plaquetas, que apesar da crescente utilização nos primeiros anos em que foi desenvolvido, alguns trabalhos indicavam limitações em relação ao seu uso, devido aos protocolos utilizados. Então, foi proposto a PRF, um agregado de segunda geração, que, por sua vez, está cada vez mais sendo utilizado na odontologia, principalmente na área da periodontia, cirurgia e implantodontia. De acordo com essa revisão, pode-se concluir que a PRF pode ser um material de escolha quando se busca resultados mais rápidos e satisfatórios em relação à cicatrização na periodontia, implantodontia e cirurgias odontológicas em geral. Além disso, é um material autólogo, de fácil obtenção e baixo custo, porém, por ser uma técnica relativamente nova, é necessária a realização de mais estudos que embasem cientificamente suas aplicações.
\end{abstract}

PALAVRAS-CHAVE: Plasma Rico em Plaquetas. Fibrina Rica em Plaquetas. Odontologia.
ABSTRACT | Tissue repair is an attribute of the organism for healing an injury, recovering the affected tissue. Fibrin plays an important role in the tissue regeneration process. It is defined as a fibrous protein that acts in blood coagulation, promoting platelet aggregation in hemostasis. Some platelet aggregates have been used in odontology to improve the tissue regeneration process: Platelet-Rich Plasma (PRP) and PlateletRich Fibrin (PRF). This work aims to analyze, through literature review, the properties of platelet aggregates, especially on PRF and its use in odontology. The first generation of autologous platelet aggregates was named Platelet-Rich Plasm. Although it was widely used in the first years of its development, some studies have pointed out limitations related to its use due to the protocols used. So, a PRF has been proposed, a second-generation aggregate that has been increasingly used in odontology, mostly in periodontics, surgery, and implantology. According to this review, it can be concluded that PRF may be a material to be chosen when faster and satisfactory results are sought for healing in implant dentistry periodontics and dental surgeries in general. Besides this, it is an easily accessible autologous material of low cost. However, because it is a relatively new technique, further studies are necessary to support its applications.

KEYWORDS: Platelet-Rich Plasma. Platelet-Rich Fibrin. Dentistry. 


\section{Introdução}

O reparo tecidual consiste na propriedade do organismo em curar uma ferida recuperando a continuidade do tecido afetado. O processo de regeneração compreende a interação de moléculas e células que promovem a recuperação funcional dos tecidos anteriormente destruídos. ${ }^{1}$

A fibrina apresenta um importante papel no processo de regeneração tecidual, sendo definida como uma proteína fibrosa que atua no processo de coagulação sanguínea promovendo agregação plaquetária durante a homeostasia. ?

A coagulação ocorre devido a substâncias denominadas fatores de coagulação. Esses fatores incluem íons cálcio, enzimas inativas e diversas moléculas associadas a plaquetas. O processo de coagulação consiste em uma cascata complexa de reações enzimáticas, na qual cada fator de coagulação ativa várias moléculas do fator seguinte e, por último, forma-se a proteína insolúvel fibrina. A coagulação sanguínea é dividida em três estágios, o primeiro consiste na formação da protrombinase pelas vias extrínseca e intrínseca, no segundo estágio, a protrombinase converte a protrombina (uma proteína plasmática formada pelo fígado) em trombina, no terceiro e último estágio, a trombina converte o fibrinogênio em fibrina insolúvel, que, por sua vez, forma os filamentos do coágulo. $\underline{2}$

Outro componente importante para regeneração tecidual são os fatores de crescimento, por estimularem a proliferação celular, angiogênese, diferenciação e síntese celular. ${ }^{3.4}$ As plaquetas, mesmo pequenas, armazenam uma impressionante variedade de substâncias; entre elas, fatores de crescimento. Nos agregados plaquetários estão presentes fator de crescimento derivado de plaquetas (PDGF) responsável por promover a proliferação de células endoteliais vasculares, fibras de músculos liso e fibroblastos, com o objetivo de ajudar no reparo tecidual. Fator de crescimento transformador beta (TGF-B) é uma proteína responsável pela regulação da inflamação através da sua capacidade para induzir a cicatrização fibrosa. O Fator de crescimento endotelial vascular (VEGF) é responsável por promover a sinalização para neoformação vascular. E, por último, fator de crescimento endotelial (EGF) é uma proteína que também promove reparação tecidual. $\underline{\text { ? }}$
Vêm sendo propostos protocolos que fazem uso de concentrados de plaquetas que mostram grandes benefícios: favorecem e aceleram o pós-cirúrgico e fornecem um suporte para regeneração tecidual. $\frac{5}{}$ Com isso, alguns materiais estão sendo utilizados na Odontologia, como: Plasma Rico em Plaquetas (PRP) e Fibrina Rica em Plaquetas (PRF).

O PRP é uma concentração autóloga de plaquetas humanas em um volume pequeno de plasma e tem em suas bases biológicas o aumento da concentração de fatores de crescimento, que são importantes no processo cicatricial. $\underline{\underline{b}}$

A PRF é um gel de fibrina autóloga, apresentando como propriedade o maior favorecimento da cicatrização de tecido moles, pois acredita-se que contenha fatores de crescimento em concentrações ainda maiores que possibilitam uma regeneração tecidual mais rápida. ${ }^{\mathrm{N}} \mathrm{Na}$ Odontologia, o seu uso está sendo frequente na implantodontia, cirurgias periodontais, tecidos moles e duros, entre outros.

Devido à aplicabilidade crescente dos agregados plaquetários, compreender melhor os seus princípios, seus potenciais e limitações são de grande importância para a indicação correta do seu uso, além da escolha do protocolo de obtenção do agregado mais adequado.

O objetivo deste trabalho é, através por meio de uma revisão de literatura discutida, analisar as propriedades dos agregados plaquetários, em especial a PRF, e a sua utilização na Odontologia.

\section{Metodologia}

O presente trabalho se trata de uma revisão de literatura discutida sobre agregados plaquetários e a sua utilização na Odontologia. Foi realizada a busca por artigos científicos nas bases de dados da Scielo, Google Acadêmico, Periódico Capes e PubMed (que compreende o Medline) durante o período de 2000 a 2018. Após a pesquisa foram priorizados artigos clássicos e mais recentes que apresentassem importância em relação ao tema supracitado e que pudessem ser citados nesta revisão e o seu acesso integral. 
Foram excluídos os artigos que não apresentaram relevância clinica quanto ao assunto ou que não pudessem ser acessados. Foram utilizados os seguintes termos: platelet rich plasma, platelet-rich fibrina, platelet-rich fibrin in dentistry, Choukroun PRF e PRF. Além disso, foram utilizados 3 livros com intuito de conceituar alguns termos, sendo os autores: Gerard Tortora e Bryan Derrickson ${ }^{12}$, Alberto Consolaro ${ }^{3}$, e, por fim, Joseph Choukroun e Richard Miron. . $^{-}$

\section{Revisão de literatura}

\section{Agregados plaquetários}

Os agregados plaquetários vêm sendo utilizados visando uma melhora na velocidade da cicatrização e da regeneração tecidual. A primeira geração de agregados plaquetários autólogos foi denominado de Plasma Rico em Plaquetas. Apesar da crescente utilização do PRP nos primeiros anos em que os agregados plaquetários foram desenvolvidos com o objetivo de auxiliar na reparação tecidual, diversos trabalhos indicavam a limitação inerente ao seu uso. A técnica para obtenção do PRP, em si, necessita de um longo tempo para preparação, colheita e centrifugação do sangue, além da adição de anticoagulante. ${ }^{7 \underline{8}}$ Consequentemente, as tentativas de desenvolver uma técnica alternativa aumentaram. Foi então que surgiu na França, desenvolvido por Choukroun, a PRF, um material que não precisa de anticoagulantes no seu preparo, tornando-se uma opção mais simples e barata para a obtenção de um agregado plaquetário autólogo. $\underline{\underline{7} .8}$

O PRP é um dos materiais investigados e utilizados para acelerar o crescimento de tecido mole e tecido duro. Este agregado é obtido através da centrifugação do sangue autólogo resultando em uma concentração de plaquetas humanas em um volume pequeno de plasma e tem em suas bases biológicas o aumento da concentração de fatores de crescimento. Tais fatores desempenham papel importante na regeneração, sendo eles fator de crescimento derivado de plaquetas (PDGF), fator de crescimento transformante beta (TGF-B), fator de crescimento endotelial vascular (VEGF) e fator de crescimento epitelial (EGF)

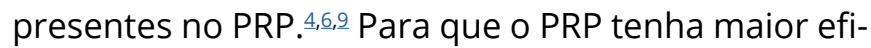
cácia, a concentração ideal de plaquetas deve ser em torno de $1.000 .000 \mu \mathrm{L}$ em $5 \mathrm{~mL} .{ }^{10}$
Em geral, os protocolos para obtenção do PRP apresentam alguns pontos em comum, pois é realizada a coleta de uma amostra de sangue juntamente com anticoagulante antes ou durante a cirurgia e imediatamente levada para a centrifugação., 4, Para que aumente a concentração de plaquetas, os protocolos descritos usam uma dupla centrifugação. A primeira centrifugação consiste em separar o sangue em três camadas distintas, a segunda centrifugação consiste também na separação de três camadas de sangue, porém, de maneira mais veloz, visando separar mais facilmente a região rica da pobre em plaquetas. $\mathrm{Na}$ primeira centrifugação encontram-se, na parte inferior do tubo, células vermelhas do sangue; na parte superior o plasma acelular ou plasma pobre em plaquetas (PPP). Intermediária a essas duas partes encontra-se uma camada mais fina denominada de buffy coat, rica em concentrações de plaquetas. Os passos seguintes podem sofrer variações, mas consistem basicamente em descartar a camada de glóbulos vermelhos e PPP, obtidos através da segunda centrifugação para obter somente o plasma rico em plaquetas. 4,711

O concentrado de plaquetas obtido é aplicado na região desejada com uma seringa, em conjunto com trombina e cloreto de cálcio, desencadeando a ativação de plaquetas e fibrina. O PRP está cada vez mais em desuso para a regeneração, pois apresenta baixa eficácia e acredita-se que isso pode estar relacionado a rápida liberação dos fatores de crescimento e a demora no processo de centrifugação. ${ }^{4}$

Devido a restrições legais em relação a manipulação de sangue, uma nova família de concentrados plaquetários surgiu na França, sendo conhecida como a segunda geração de agregados plaquetários autólogos, a fibrina rica em plaquetas. ${ }^{4, Z}$ Esse material não é simplesmente uma cola de fibrina nem tampouco um concentrado de plaquetas clássico. É definido como um gel de fibrina autólogo, apresentando como propriedade o maior favorecimento da cicatrização de tecido moles, pois acredita-se conter fatores de crescimento em concentrações ainda maiores que possibilitam uma regeneração tecidual mais rápida. A PRF é um aditivo cirúrgico bioativo, rico em plaquetas, fatores de crescimento e leucócitos, que regulam a inflamação e estimulam a regeneração., 4, 
O coágulo de PRF é considerado uma matriz favorável para migração de células endoteliais e fibroblastos para dentro dos tecidos lesionados. ${ }^{12}$ Consequentemente, acelera o processo de angiogênese facilitando a cicatrização dos tecidos envolvidos. Portanto, a membrana de PRF pode ser utilizada em todo tipo de pele ou mucosas. 12

Para a obtenção da PRF não é necessário uso de anticoagulantes, dessa forma passou a ser uma alternativa simples e barata para a obtenção de um agregado plaquetário autólogo. A PRF não é apenas uma membrana de fibrina, é uma matriz que contém todos os elementos celulares e moleculares presentes no sangue que favorecem a regeneração. Estão presentes nessa matriz um elevado concentrado de plaquetas, fatores de crescimento, citocinas, leucócitos e células estaminais circulantes. Devido a isso, esse material pode ser considerado um concentrado fisiológico.,12,13

Existem diferentes protocolos para a obtenção da PRF. No protocolo proposto por Dohan et al. ${ }^{7}$ e Mourão et al. ${ }^{14}$, uma amostra de sangue é coletada, por volta de $10 \mathrm{ml}$, no pré-operatório ou durante a cirurgia através de punção da veia do paciente, em seguida o sangue é centrifugado a 3000 rpm aproximadamente durante 10 minutos, sem a utilização de anticoagulantes, com isso obtém-se a membrana de PRF pronta para ser utilizada no local em que se deseja. (Figura 1A e 1B). A ausência de anticoagulante implica na ativação das plaquetas em poucos minutos, quase que imediatamente após o contato com o vidro do tubo.

Figura 1. 1A - Membrana de PRF após ser removida do tubo de ensaio. 1B - Membranas de PRF prontas para uso

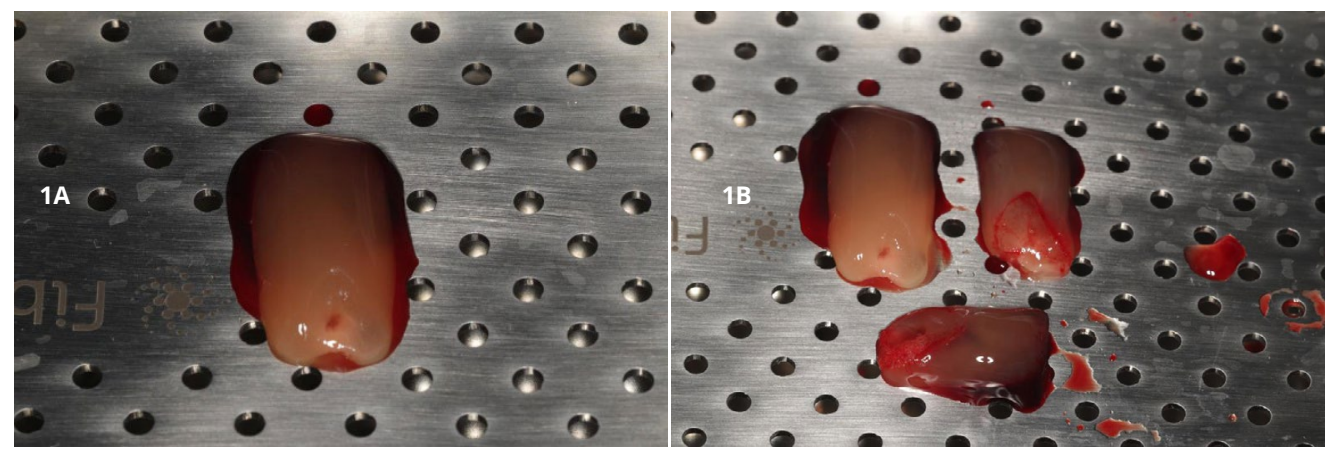

O produto obtido pode ser utilizado na forma de coágulo ou após a compressão do mesmo como uma membrana densa e, ademais, na forma líquida e incorporado ao osso mineralizado, transformando-se em um compósito mineralizado à base de fibrina. ${ }^{13-15}$

O sucesso deste procedimento depende inteiramente da velocidade da coleta de sangue e da centrifugação. A priori, a execução da técnica de maneira rápida é a única forma de obter um coágulo de PRF em consistência adequada. Se o tempo de preparo do coágulo for excessivo, possivelmente a fibrina irá polimerizar de modo difuso e sem consistência, perdendo as suas propriedades. ${ }^{?}$

A fibrina rica em plaquetas e leucócitos (L-PRF) é uma variação da fibrina rica em plaquetas, um agregado plaquetário de segunda geração que pode ser distinguido segundo Dohan Ehrenfest et al. 4 em três parâmetros, sendo eles, a densidade da fibrina, a quantidade de leucócitos e a padronização do procedimento. A L-PRF é um material que contém na sua matriz plaquetas, leucócitos, fatores de crescimento e citocinas circulantes, obtidos a partir de uma coleta de sangue que é posteriormente centrifugado sem anticoagulantes. Para o aumento da quantidade leucocitária aumenta-se a potência do equipamento durante a centrifugação.,112

Já a fibrina rica em plaquetas injetável (I-PRF), da mesma forma que a fibrina leucocitária, é uma variação da PRF muito empregada em procedimentos de harmonização orofacial e incorporado a osso mineralizado resultando no stick bone (Figura 2). Tal material pode ser manuseado na forma liquida ou injetável sendo adquirido após a centrifugação do sangue autólogo e retirado com auxílio de uma seringa. ${ }^{14}$ 


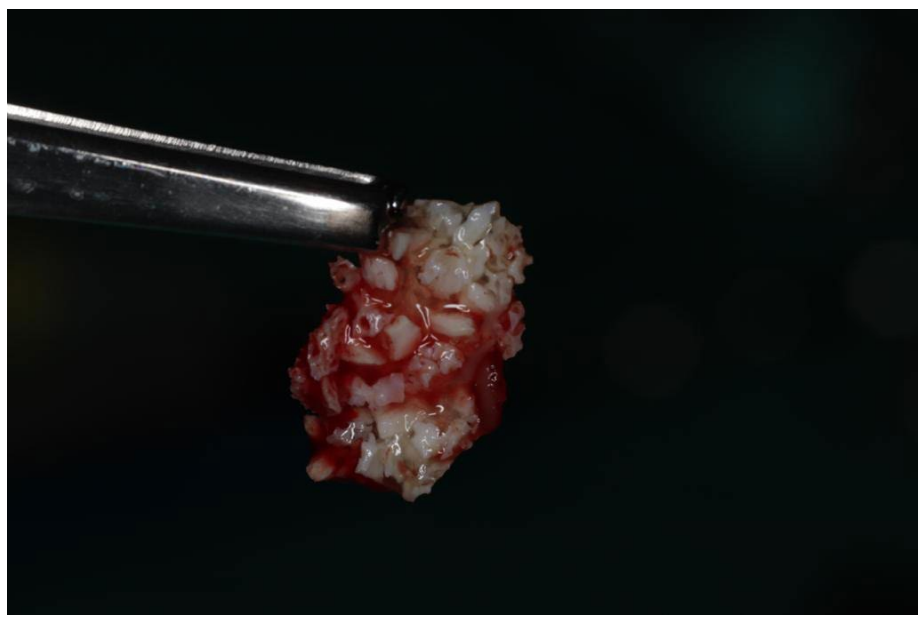

Faz-se então a coleta de $9 \mathrm{~mL}$ de sangue que serão centrifugados a $3.300 \mathrm{rpm}$ por 2 minutos. Após, é coletado com uma seringa apenas o I-PRF, obtendo-se em torno de $5 \mathrm{~mL}$.

Abaixo foi desenvolvido um quadro (quadro 1) que sintetiza algumas propostas de protocolos para obtenção da PRF.

Quadro 1. Protocolos para obtenção da PRF

\begin{tabular}{|c|c|c|}
\hline AUTOR/ESTUDO & MATERIAL A SER OBTIDO & $\begin{array}{l}\text { PROTOCOLO DE } \\
\text { CENTRIFUGAÇÃO }\end{array}$ \\
\hline Dohan et al. ${ }^{7}$ e Mourão et al. ${ }^{14}$ & Fibrina Rica em Plaquetas (PRF). & $\begin{array}{l}\text { Coleta de } 10 \mathrm{~mL} \text { de sangue que } \\
\text { serão centrifugados a } 3.000 \mathrm{rpm} \\
\text { durante } 10 \text { minutos. }\end{array}$ \\
\hline Ehrenfest et al. ${ }^{4}$ & $\begin{array}{l}\text { Fibrina Rica em Plaquetas e } \\
\text { Leucócitos (L-PRF). }\end{array}$ & $\begin{array}{l}\text { É uma variação da PRF } \\
\text { aumentando apenas a potência da } \\
\text { centrifugação. } \\
\text { Coleta de } 10 \mathrm{~mL} \text { de sangue } \\
\text { aumentando a potência da } \\
\text { centrifuga acima de } 3.000 \mathrm{rpm} \text { por } \\
10 \text { minutos. }\end{array}$ \\
\hline Mourão et al. ${ }^{14}$ & $\begin{array}{l}\text { Fibrina Rica em Plaquetas Injetável } \\
\text { (I-PRF). }\end{array}$ & $\begin{array}{l}\text { Também é uma variação da PRF, } \\
\text { utilizada de forma líquida ou } \\
\text { incorporada a osso mineralizado. } \\
\text { Coleta de } 9 \mathrm{~mL} \text { de sangue } \\
\text { centrifugados a } 3.300 \text { rpm por } 2 \\
\text { minutos. Após, é coletado com } \\
\text { uma seringa apenas o I-PRF em } \\
\text { torno de } 5 \mathrm{~mL} \text {. }\end{array}$ \\
\hline
\end{tabular}

Diante dos resultados expostos, há evidências que o uso da PRF apresenta um melhor funcionamento em relação ao PRP no que diz respeito à velocidade e qualidade da regeneração tecidual, isto acontecendo devido às diferenças básicas.

O uso do PRP objetiva auxílio na regeneração tecidual por meio de plaquetas e fatores de crescimento presentes em sua base biológica. ${ }^{-}$Entretanto, tornou-se uma técnica relativamente ineficaz devido ao tempo prolongado de obtenção. Além disso, requer a adição de anticoagulantes e posteriormente é incorporado, ao material obtido, cloreto de cálcio e trombina bovina. Transformou-se em uma técnica mais complexa e de alto custo.4.,11 Por causa de tais problemas, foi desenvolvida uma nova metodologia possibilitando melhorias na regeneração tecidual. 
A PRF apresenta características distintas como a presença de plaquetas, fatores de crescimento em quantidades ainda maiores, citocinas e leucócitos na sua matriz. Após a coleta do sangue, o material é imediatamente centrifugado uma única vez, sem adição de quaisquer anticoagulantes. Em suma, tornou-se um método de baixo custo apresentando um preparo simplificado e rápido que está diretamente relacionado com o sucesso para acelerar e melhorar a regeneração.,, , 12,13

\section{PRF e seu uso na odontologia}

\section{Periodontia}

Lekovic et al. ${ }^{16}$ realizaram um estudo com dezessete pessoas sistemicamente saudáveis e doze fumantes. Um grupo recebeu PRF e outro PRF associado com BPMB (osso mineral poroso bovino). Os critérios de inclusão foram a presença de defeito com profundidade de sondagem $>6 \mathrm{~mm}$. Realizou-se terapia inicial com instrução de higiene oral e raspagem e alisamento radicular, seis a oito semanas antes do procedimento cirúrgico. Anteriormente à cirurgia foram coletados $10 \mathrm{~mL}$ de sangue de cada paciente, colocados em tubos sem anticoagulantes e centrifugados por $10 \mathrm{~min}$ a $1000 \mathrm{rpm}$. Como resultado, o grupo que utilizou somente PRF apresentou melhora nos parâmetros clínicos, diminuindo os defeitos infra-ósseos, em contrapartida o grupo que recebeu PRF associada ao BPMP teve resultados mais expressivos, pois tal produto intensifica a ação da PRF reduzindo as bolsas periodontais, aumentando níveis de inserção clínica e corrigindo defeitos infra-ósseos. Apesar dos resultados obtidos serem satisfatórios este trabalho não comprova os benefícios da PRF já que não se obteve um grupo controle para comparar os resultados sem o uso do agregado plaquetário.

Verma et al. ${ }^{17}$ concluíram, em uma revisão sistemática, que a PRF é um material com grande potencial regenerativo utilizado na área médica e odontológica. O seu uso sozinho ou associado a outros biomateriais como enxertos ósseos, enxerto de tecidos moles e agentes farmacológicos, fornecem resultados seguros e promissores no que diz respeito à melhora nos parâmetros clínicos e radiográficos relacionados a defeitos ósseos periodontais. Entretanto, no que diz respeito à cobertura de raízes que possuíam recessões, os resultados não foram tão favoráveis, embora promovessem melhora da espessura do tecido gengival.

Analisando o efeito da PRF na periodontia percebeu-se resultados favoráveis e semelhantes. Lekovic et al. ${ }^{16} \mathrm{e}$ Verma et al..$^{17}$ afirmam que tal agregado plaquetário minimiza os defeitos ósseos e apresentam uma meIhoria nos parâmetros clínicos e radiográficos, além de que, concordam que a PRF associada com outros biomateriais promovem uma ação mais expressiva dos resultados. Contudo, são necessários mais estudos clínicos controlados para se firmar o real efeito da PRF na terapia regenerativa periodontal.

\section{Implantodontia e Seio Maxilar}

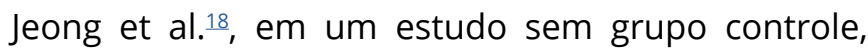
analisaram em 6 cães o efeito da PRF na elevação do seio maxilar acompanhado da instalação de implantes. Foram coletados $20 \mathrm{~mL}$ de sangue centrifugados a 2400 rpm durante 10 minutos. Realizou-se então a cirurgia para levantamento da membrana do seio maxilar seguido da instalação dos implantes, posteriormente a área entre a membrana e o implante foi preenchida com fibrina rica em plaquetas e foi realizada a sutura. Seis meses após a realização do procedimento um exame macroscópico mostrou que a região em que foi colocada a membrana de PRF entrou em colapso, além disso os implantes instalados não foram recobertos por osso. Concluindo que a elevação do seio maxilar simultânea a instalação de implantes utilizando a PRF como único material de enxerto não é um procedimento previsível e reprodutível, além disso, não foi observado formação óssea ao redor dos implantes.

Mourão et al. ${ }^{19}$ produziram um relato de caso com o objetivo de analisar a eficácia do coágulo de PRF para a proteção de materiais como enxerto ósseo e implantes. Colheu-se $12 \mathrm{~mL}$ de sangue que foram centrifugados a $2400 \mathrm{rpm}$ por 10 minutos. Os implantes foram instalados seguidos da colocação de enxerto ósseo e posteriormente aplicou-se o coágulo da PRF por último foram realizadas as suturas. Concluíram que a PRF é um material autólogo que favorece a regeneração tecidual e que serve como uma barreira protetora para o enxerto ósseo colocado na cavidade oral.

Öncü et al. ${ }^{20}$ realizaram um estudo com o objetivo de avaliar a eficácia da fibrina rica em plaquetas nas perfurações da membrana do seio maxilar. 
Foram selecionados 16 pacientes; entre eles, pacientes com e sem perfuração da membrana do seio maxilar. A altura do osso remanescente foi medida antes da realização da cirurgia. Foram realizados procedimentos para obtenção da PRF colhendo $9 \mathrm{ml}$ de sangue imediatamente centrifugados a $2700 \mathrm{rpm}$ durante 12 minutos e, posteriormente, o levantamento da membrana do seio maxilar. As membranas de PRF foram colocadas exatamente onde as perfurações foram observadas. Após, tanto as áreas com e sem perfuração de seio foram continuadas com material de enxerto ósseo. Em seguida, foram feitas as colocações dos implantes. Como resultados, os grupos apresentaram neoformação óssea no assoalho do seio maxilar, além de ser observado o ganho ósseo ao redor dos implantes. Concluindo que não houve diferença entre os grupos, ambos apresentaram ganho ósseo semelhante e possível vasculogênese.

Portanto, os trabalhos vêm demonstrando que a PRF pode ser um adjuvante na cirurgia de levantamento de seio maxilar, mas não deve ser utilizada como uma monoterapia substituindo enxertos de biomateriais. Além disso, a PRF pode ser utilizada para potencializar a regeneração tecidual na cirurgia de implantes.

\section{Alvéolos após extração}

Ozgul et al._1 realizaram estudo com 56 pessoas para avaliarem a eficácia da PRF na redução da dor e inchaço após a cirurgia para remoção bilateral de terceiros molares impactados. Foram recolhidos $10 \mathrm{ml}$ de sangue de cada paciente, adicionados em um tubo sem anticoagulante e levados imediatamente para centrifuga programada para 3000rpm por 10 minutos. Após a remoção das unidades, a PRF em forma de membrana foi colocada apenas em um dos alvéolos. O lado oposto foi utilizado como controle. Os resultados encontrados mostraram que a PRF é eficaz no que diz respeito à diminuição do inchaço pós-operatório, contudo, não apresentou efeito na diminuição da dor.

Marenzi et al. $\underline{22}$ selecionaram 26 pacientes que necessitavam realizar extrações simples bilaterais com o objetivo de analisar a eficácia de L-PRF em tecidos moles e na redução da dor após as extrações. O protocolo utilizado foi a colheita de $9 \mathrm{~mL}$ de sangue, inseridos em tudo sem anticoagulante e centrifugados a 2700rpm durante 12 minutos obtendo-se o coágulo de L-PRF que foi posteriormente condensado e transformado em membrana. As cirurgias foram consumadas sendo que apenas um lado receberia a membrana de L-PRF e o outro lado foi utilizado como controle. Os resultados demonstraram que o lado que foi preenchido com L-PRF apresentou diminuição da dor no pós-operatório, acelerou o processo cicatricial dos tecidos moles, reduzindo os efeitos de inflamação. Dessa forma, considerou-se o emprego de L-PRF útil e eficaz.

Zhang et al. ${ }^{23}$ analisaram o efeito da fibrina rica em plaquetas na preservação alveolar após extração dentária em 28 pacientes divididos em dois grupos. Recolheu $9 \mathrm{~mL}$ de sangue de cada paciente adicionados a um tubo sem anticoagulante e levado para centrifuga por 10 minutos. Realizaram, então, as cirurgias para extrações, sendo que apenas um grupo recebeu a membrana de PRF no alvéolo que foi posteriormente suturado. $\mathrm{O}$ grupo controle foi apenas suturado. Como resultado o grupo experimental relatou uma diminuição da dor e inchaço além de ter sido observado uma cicatrização mais rápida num período de 7 dias em comparação ao grupo controle. Entretanto a PRF não foi suficiente para minimizar a reabsorção óssea, contudo, ajudou na qualidade do osso remanescente.

O uso da PRF em alvéolos após extrações trouxe resultados favoráveis e contraditórios entre os autores dessa revisão. Ozgul et al. ${ }^{21}$ afirmam que a PRF é eficaz apenas na diminuição do inchaço pós-operatório não apresentando resultados pertinentes para a diminuição da dor após as extrações. Já Marenzi et al. ${ }^{22}$ e Zhang et al. ${ }^{23}$ certificam que tanto a dor quanto o inchaço têm uma redução significativa no pós-operatório quando se utiliza o coágulo de PRF, além de que, aceleram o processo de cicatrização. Desta maneira, é necessário a realização de mais estudos para comprovar a eficácia da PRF para diminuição da dor após extrações de terceiros molares impactados.

Vale salientar que os autores utilizaram protocolos diferentes para a obtenção do material, entretanto, chegaram a resultados semelhantes e favoráveis em alguns pontos, divergindo apenas no quadro de dor pós-operatória. 


\section{Endodontia Regenerativa}

Os estudos para o uso da PRF na endodontia ainda são incipientes, porém, Bakthtiar et al. $\stackrel{24}{ }$ afirmam que a membrana de PRF é um bom recurso para indução da regeneração celular e tecidual, contudo são necessários estudos para saber precisamente como acontece a ação de PRF na regeneração da polpa dentária.

Sharma et al. ${ }^{25}$ asseguram que o uso da PRF associado com MTA (agregado trióxido mineral) forma uma barreira cementária e periodontal mais resistente no ápice radicular facilitando e acelerando o processo de cicatrização.

Prasad et al. $\underline{26}$ concluíram que em dentes que necessitam de retratamento endodôntico a PRF é eficiente na regeneração celular da polpa dentária sendo capaz de induzir a apicogênese.

$\mathrm{Na}$ endodontia, os autores obtiveram resultados favoráveis, tanto Bakthtiar quanto Prasad afirmam que a PRF é eficiente na regeneração da polpa dentária além de induzirem a formação dos tecidos. Sharma afirma ainda que o material autólogo quando usado em conjunto com outros materiais tem um efeito sinérgico além de apresentar um processo regenerativo mais rápido. $24-26$

É notório que a PRF vem sendo utilizada cada vez mais na área odontológica e em sua maioria apresentam resultados satisfatórios, entretanto, sugere-se a realização de estudos futuros que avaliem a possibilidade da padronização do protocolo de obtenção do material autólogo e, assim, afirmar se os resultados serão mais fidedignos e semelhantes.

\section{Considerações finais}

De acordo com o que foi exposto nesta revisão, pode-se concluir que a PRF é um material com potencial para ser eleito quando se busca resultados mais rápidos e satisfatórios no que diz respeito à regeneração tecidual. Além disso, tem melhores resultados quando associada a outros biomateriais.
Pode-se afirmar, ainda, que a PRF é um agregado plaquetário autólogo de fácil obtenção e baixo custo, porém, por ser uma técnica relativamente nova, é necessária a realização de mais estudos que embasem cientificamente suas aplicações.

\section{Contribuições das autoras}

Alves LES participou da concepção, realizou a busca e revisão dos artigos científicos e foi responsável pela redação do artigo. Barbosa MDS participou da idealização do projeto, definição de tema, delineamento e revisão da redação, além de direcionar autores importantes para a construção do artigo.

\section{Conflitos de interesses}

Nenhum conflito financeiro, legal ou político envolvendo terceiros (governo, empresas e fundações privadas, etc.) foi declarado para nenhum aspecto do trabalho submetido (incluindo, mas não se limitando a subvenções e financiamentos, participação em conselho consultivo, desenho de estudo, preparação de manuscrito, análise estatística, etc.).

\section{Referências}

1. Tortora GJ, Derrickson B. Principios de Anatomia e fisiologia. Rio de Janeiro: Guanabara Koogan; 2016. p. 146-65.

2. Tortora GJ, Derrickson B. Principios de Anatomia e fisiologia. Rio de Janeiro: Guanabara Koogan; 2016. p. 665-91.

3. Consolaro A. Inflamação e reparo: um sílabo para a compreensão clínica e implicações terapêuticas. Maringá: Dental Press; 2015. p. 252-7.

4. Ehrenfest DMD, Rasmusson L, Albrektsson T. Classification of platelet concentrates: from pure platelet-rich plasma (P-PRP) to leucocyte- and platelet-rich fibrin (L-PRF). Trends Biotechnol. 2009;27(3):158-67. https://doi.org/10.1016/j.tibtech.2008.11.009

5. Tatullo M, Marrelli M, Paduano F. The Regenerative Medicine in Oral and Maxillofacial Surgery: The Most Important Innovations in the Clinical Application of Mesenchymal Stem Cells. Int J Med Sci. 2015;12(1):72-7. https://doi.org/10.7150/ijms.10706

6. Marx RE. Platelet-Rich Plasma: Evidence to Support Its Use. J Oral Maxillofac Surg. 2004;62(4):489-96. https://doi.org/10.1016/j. joms.2003.12.003 
7. Dohan DM, Choukroun J, Diss A, Dohan SL, Dohan AJ, Mouhyi J, et al. Platelet-rich fibrin (PRF): A second-generation platelet concentrate. Part I: Technological concepts and evolution. Oral Surg Oral Med Oral Pathol Oral Radiol Endod. 2006;101(3):e37-44. https://doi.org/10.1016/j.tripleo.2005.07.008

8. Choukroun J, Miron RJ. Platelet Rich Fibrin in Regenerative Dentistry. Oxford: Wiley-Blackwell; 2017. p. 1-14.

9. Marx RE, Carlson ER, Eichstaedt RM, Schimmele SR, Strauss JE, Georgeff KR. Platelet-rich plasma Growth factor enhancement for bone grafts. Oral Surg Oral Med Oral Pathol Oral Radiol Endod. 1998;85(6):638-46. https://doi.org/10.1016/j.tripleo.2005.07.008

10. Marx RE. Platelet-Rich Plasma (PRP): What Is PRP and What Is Not PRP? Implant Dent. 2001;10(4):225-8. https://doi. org/10.1097/00008505-200110000-00002

11. Amable PR, Carias RB, Teixeira MV, Pacheco IC, Amaral RJC, Granjeiro JM, et al. Platelet-rich plasma preparation for regenerative medicine: optimization and quantification of cytokines and growth factors. Stem Cell Res Ther. 2013;4(3):67. https://doi.org/10.1186/scrt218

12. Choukroun J, Diss A, Simonpieri A, Girard MO, Schoeffler C, Dohan SL, et al. Platelet-rich fibrin (PRF): A second-generation platelet concentrate. Part IV: Clinical effects on tissue healing. Oral Surg Oral Med Oral Pathol Oral Radiol Endod. 2006; 101(3):e56-60. https://doi.org/10.1016/j.tripleo.2005.07.011

13. Ehrenfest DMD, Del Corso M, Diss A, Mouhyi J, Charrier JB. Three-dimensional architecture and cell composition of a Choukroun's platelet rich fibrin clot and membrane. J Periodontol. 2010; 81(4):546-55. https://doi.org/10.1902/jop.2009.090531

14. Mourão CFAB, Valiense $H$, Melo ERM, Mourão NBMF, Maia MDC. Obtenção da fibrina rica em plaquetas injetável (i-PRF) e sua polimerização com enxerto ósseo: nota técnica. Rev Col Bras Cir. 2015;42(6):421-3. https://doi.org/10.1590/0100-69912015006013

15. Chang YC, Zhao JH. Effects of platelet rich fibrin on human periodontal ligament fibroblasts and application for period ntal infrabony defects. Aust Dent J. 2011;56(4):365-71. https://doi. org/10.1111/j.1834-7819.2011.01362.x

16. Lekovic V, Milinkovic I, Aleksic Z, Jankovic S, Stankovic $P$, Kenney EB, et al. Platelet rich fibrin and bovine porous bone mineral vs. platelet-rich fibrin in the treatment of intrabony periodontal defects. J Periodontal Res. 2012; 47(4):409-17. https:// doi.org/10.1111/j.1600-0765.2011.01446.x

17. Verma U, Yadav R, Dixit M, Gupta A. Platelet-rich fibrin: A paradigm in periodontal therapy. J Int Soc Prev Community Dent. 2017;7(5):227-33. https://doi.org/10.4103/jispcd.jispcd_429_16
18. Jeong SM, Lee CU, Son JS, Oh JH, Fang Y, Choi BH. Simultaneous sinus lift and implantation using platelet-rich fibrin as sole grafting material. J Craniomaxillofac Surg. 2014;42(6):9904. https://doi.org/10.1016/j.jcms.2014.01.021

19. Mourão CFA, Mourão NBMF. Platelet-rich fibrin membrane in immediate dental implant loading. Dental Press Implantol [Internet]. 2015;9(1):104-9. Disponível em: https://www.researchgate.net/profile/Carlos-FernandoMourao/publication/282523632 Platelet-rich fibrin membrane_in_immediate_dental_implant_loading/ links/5656fc1108ae4988a7b51902/Platelet-rich-fibrin-membranein-immediate-dental-implant-loading.pdf

20. Öncü E, Kaymaz E. Assessment of the effectiveness of platelet rich fibrin in the treatment of Schneiderian membrane perforation. Clin Implant Dent Relat Res. 2017;19(6):1009-14. https://doi.org/10.1111/cid.12528

21. Ozgul O, Senses F, Er N, Tekin U, Tuz HH, Alkan A, et al. Efficacy of platelet rich fibrin in the reduction of the pain and swelling after impacted third molar surgery: randomized multicenter splitmouth clinical trial. Head Face Med. 2015;26;11:37. https://doi. org/10.1186/s13005-015-0094-5

22. Marenzi G, Riccitiello F, Tia M, di Lauro A, Sammartino G. Influence of Leukocyte- and Platelet-Rich Fibrin (L-PRF) in the Healing of Simple Postextraction Sockets: A SplitMouth Study. Biomed Res Int. 2015;2015:369273. https://doi. org/10.1155/2015/369273

23. Zhang Y, Ruan Z, Shen M, Tan L, Huang W, Wang L, et al. Clinical effect of platelet-rich fibrin on the preservation of the alveolar ridge following tooth extraction. Exp Ther Med. 2018;15(3):2277-86. https://dx.doi.org/10.3892\%2Fetm.2018.5696

24. Bakhtiar H, Esmaeili S, Tabatabayi SF, Ellini MR, Nekoofar $\mathrm{MH}$, Dummer PM. Second-generation Platelet Concentrate (Platlet-rich Fibrin) as a Scaffold in Regenerative Endodontics: A Case Series. J Endod. 2017;43(3):401-8. https://doi.org/10.1016/j. joen.2016.10.016

25. Sharma S, Grover S, Dudeja P, Sharma V, Passi D. NonSurgical Management of Teeth with Wide Open Apices and Large Periapical Lesions: A Conservative Reality. J Clin Diagn Res. 2016;10(11):Zj01-2. https://doi.org/10.7860/jcdr/2016/21520.8765

26. Prasad J, Ataide IN, Chalakkal P, Likhyani LK. Comparison between the Outcomes of Two Platelet-Rich Concentrates on Apexogenesis in Young Permanent Incisors Requiring Endodontic Retreatment. Contemp Clin Dent. 2018; 9(Suppl 1): S156-9. https://doi.org/10.4103/ccd.ccd 918 